\title{
Analysis of Senior High School Students' Competency in General Mathematics
}

\author{
Leo A. Mamolo \\ College of Education, Visayas State University, Philippines
}

Copyright $(\mathrm{O} 2019$ by authors, all rights reserved. Authors agree that this article remains permanently open access under the terms of the Creative Commons Attribution License 4.0 International License

\begin{abstract}
After a country-wide full blast implementation of a K-12 program, a detailed assessment of the curriculum has to take place. This study analyzed the General Mathematics competency of 425 Grade 12 students during the 2017-2018 school year. The study employed a validated researcher-made General Mathematics Competency test with an acceptable 0.788 Cronbach's alpha. Results showed that all strands in the Technical Vocational and Livelihood (TVL) track, and the Accountancy, Business, and Management (ABM), Humanities and Social Sciences (HUMSS), and General Academic (GA) strands of the academic track were fair in competency. Only the Science, Technology, Engineering, and Mathematics (STEM) strand got a satisfactory level. Between the two tracks, the academic track has significantly different competency compared to the TVL track. On the academic strands, STEM has significantly different competency compared to other strands. On the TVL strands, Computer Servicing System (CSS) has significantly different competency compared to the other strands. Moreover, data revealed that the least learned competencies of students were distributed in the three areas of General Mathematics. The data may indicate that high school seniors have not yet mastered the necessary competencies in the subject matter as stipulated by the Department of Education.
\end{abstract}

Keywords Competency Assessment, Senior High School, Academic Track, TVL Track, Least Learned Skills

\section{Introduction}

Assessment is an essential part in the teaching-learning process. Students' performance in their chosen field can be measured through assessment. According to Wiliam [1], the word assessment is mainly used to describe the ways in evaluating the effectiveness of series of instructional activities after those were finished. He also emphasized that assessment can potentially improve learning under certain conditions. Moreover, the Department of Education Order No. 8 series of 2015 defined assessment as "a process that is used to keep track of learners' progress in relation to learning standards and in the development of 21 st century skills; to promote self-reflection and personal accountability among students about their own learning; and to provide the bases for the profiling of student performance on the learning competencies and standards of the curriculum." [2].

With the advent of the K-12 Program in the country via the Republic Act 10533, a competency-based assessment was emphasized. Hartel and Foegeding [3] defined competency as a general statement that details the desired knowledge and skills of a student finishing a course or program. When people perform in professional, educational, and other life contexts using applied skills and knowledge successfully, that's competency. Similarly, Laine et al. [4] differentiated that in a traditional model of education, student achievement refers to time spent in a classroom expecting all students to proceed to the next step at the same pace since they were taught as a group. In Competency-Based Education (CBE), assessment of students' prior knowledge is the first step, then allowing them to move to the next step based on their acquired knowledge and skills; hence, CBE encourages students' success because it provides targeted learning support for creating a more personalized educational experience. In a book entitled, Blended: Using Disruptive Innovation to Improve Schools, competency-based learning is defined as "the idea that students must demonstrate mastery of a given subject...before moving on to the next one. Students don't move on from a concept based on the average pace of the class or within a preset and fixed amount of time" [5]. Hence, competency-based education, which is also coined as mastery-based, performance-based and proficiency-based has gained drive and attention [6]

For the Senior High School program in the Philippines, Magno and Piosang [7] reported six levels of assessment, which include Placement of students in the senior high school tracks, Classroom-based assessment, Assessment of 
achieved competencies, Participation in international benchmarking of competencies, College readiness assessment, and Career assessment. According to the authors, policy makers, curriculum developers, teachers, and school administrators may benefit from these reports of assessment. Hence, better assessment as an integral part of the curricular programs in schools and within education at a national level may be developed and implemented. All of these are done in ensuring the quality of implementation [7].

Furthermore, in the senior high school, General Mathematics is one of the core subjects to be taken by all strands. It aims to provide students with an understanding of how to solve problems involving rational, exponential and logarithmic functions; to solve business-related problems, and to apply logic to real-life situations. Thus, all its learning competencies are geared towards helping equip students with the necessary knowledge and skills needed in university life and the workplace. It is in line with the Department of Education's aim that the curriculum is inclusive and built around the learners' and community's need and is standards- and competency-based. Moreover, it proposes to develop and harness the skills and competencies of the Filipino youth, leading to the development of self, community, and nation. As such, these competencies need to be acquired before graduation [8].

However, those envisioned goals of the Department of Education on having a successful teaching and learning process may be compromised by the fact that General Mathematics has plenty of learning competencies that must be taught for only 80 hours in a semester. Despite the effort like provision and utilization of Information and Communication Technology (ICT) as a strategy to improve the access to quality of education; giving learners access to enough and diverse human, institutional, and instructional resources; and many others, teaching plenty of learning competencies with a given short period of time may cause a problem.

Thus, the need for assessment is essential which is in line with the Department of Education's goal to have "a thorough review" of the curriculum. This study may provide part of the data that the department is looking for. Moreover, the data gathered will be of help to the Commission on Higher Education (CHED) for they highlighted that the development of K-12 in basic education program has inevitable effect on the university/college curriculum and the personnel who will be involved in the higher education sector [9]. Furthermore, this study adds to the body of literature on the new curriculum and its effect on the academic outcomes of students.

This study aimed to analyze the competency of senior high school students in General Mathematics in a public senior high school division in Central Philippines of School Year 2017-2018. To reach the aim of this study, the researchers have addressed the following research questions:

1. What is the competency of the SHS students in General Mathematics under:

A)Academic Track

1) Accountancy, Business, and Management (ABM) Strand

2) General Academic (GA) Strand

3) Humanities and Social Sciences (HUMSS) Strand

4) Science, Technology, Engineering, and Mathematics (STEM) Strand

B) Technical Vocational Livelihood Track

1) Computer Servicing System (CSS) Strand

2) Home Economics (HE) Strand

3) Others (Dressmaking, Caregiving, Automotive, Crop Production, etc.)

2. Is there a significant difference in the competency of SHS students in General Mathematics:

1) Among the strands of the academic track?

2) Among the strands of the TVL track?

3) Between Academic and TVL track?

3. What are the least learned competencies of senior high school students in General Mathematics?

\section{Materials and Methods}

\subsection{Research Design}

In this descriptive study, the survey model was used. According to Stangor (2011), descriptive research creates a picture of the current scenario by providing a relatively complete representation of what is happening at the moment. One of the methods of a descriptive study is survey. In this study, high school seniors were surveyed using test questionnaire to analyze their competency in General Mathematics [10].

General Mathematics is chosen as the subject matter where students' competency was assessed since it is one of the two core subjects under the Mathematics area which were taken by all senior high school students. Choosing one core Mathematics subject is decided to be in line of the goal of the Department of education's goal towards having detailed review of the curriculum.

The study used the General mathematics test. After students answered the test, their competency was then recorded and analyzed.

\subsection{Study Group}

This study involved a random samples of senior high school students in 7 public senior high schools of one school division of Department of Education Region 8, 
Philippines during the School Year 2017-2018. The Academic and TVL tracks students were the participants of the study. Of the 425 students who participated; 230 students are from the academic track, and 195 students come from the TVL tack. All were grade 12 students during the study. Information about the research was given to the students prior to the study. Those who wanted to participate voluntarily were part of the research.

\subsection{Data Collection Tool}

To collect the data, the 80-item researcher-made General Mathematics Competency Test was the primary instrument used. This instrument included: 1) Personal Information Form and 2) 80-item Competency Test.

\subsubsection{Personal Information Form}

The researcher used the "Personal Information Form" to collect data regarding students tracks and strands in the senior high school program.

\subsubsection{0-item Competency Test}

This test is used in assessing the Senior High School competency in General Mathematics. The test covered the learning competencies of the core subject-General Mathematics as stipulated in the curriculum guide of the Senior High program.

General Mathematics was taught for 80 hours in a semester and the researcher allotted questions for all the learning competencies covered. In the table of specification, if a certain learning competency was taught for 1 hour, one question was made for that competency. Moreover, if it was taught for 3 hours, there were three questions for that competency at a different level of difficulty. This was done to cover all competencies as stipulated and to have a fair distribution of the questions in the exam. This test underwent face and content validity by eight Mathematics experts. After integrating the corrections, it was pilot-tested to Grade 12 students and determined that the Cronbach's alpha value for internal consistency is 0.788 .

The competency of the students was based on the point percentage the students got on the 80 -item competency test. Student competency was described by levels, which were also validated by experts. The levels are:

$\begin{array}{ll}\text { Score } & \text { Description } \\ 64.01-80.00 & \text { Excellent } \\ 48.01-64.00 & \text { Very Satisfactory } \\ 32.01-48.00 & \text { Satisfactory } \\ 16.01-32.00 & \text { Fair } \\ 0-16.00 & \text { Poor }\end{array}$

\subsection{Data Analysis}

The data was collected via the paper-based General Mathematics Competency Test.
After the data collection, data had been analyzed using SPSS Version 21.0. Mean and standard deviation were used to describe the competency of the senior high school students. Frequency counts was used to rank the least learned competency in General Mathematics. T-test for independent sample was used for comparison of the two tracks, while the analysis of variance was used for multiple comparisons. Scheffe-test was used for the post hoc analysis. P-value is set into 0.05 .

\section{Findings}

Data were analyzed and presented in tables in the following.

Table 1 showed that the Academic Track were fair in competency $(M=26.40, S D=7.12)$. This means that generally, students in the Academic Track have Fair Competency in General Mathematics, which includes the learning competencies in Functions and their Graphs, Business Mathematics, and Logic Areas. In other words, most of the students only got scores ranging from 16-32 points out of the 80 -item competency test given.

Moreover, the table revealed that in the four strands of the Academic Track, only the STEM received a competency rating of satisfactory $(M=33.40, S D=6.62)$ while the others have fair competency; ABM $(M=26.70$, $S D=6,51)$, HUMMS $(M=23.36, S D=4.52)$ and GA $(M=22.37, S D=4.50)$. This signifies that primarily the STEM strand students received scores ranging from 32-48 points on the 80-item competency test given.

Table 1 also showed the competency of Senior High School Students in General Mathematics of the Technical Vocational and Livelihood (TVL) Track and its strands. The result showed that the students in the TVL track were fair in competency $(M=23.09, S D=5.25)$. Furthermore, the table revealed that all the strands of the TVL track got a fair competency; Computer System Servicing $(M=25.89$, $S D=5.64)$, Home Economics $(M=21.09, S D=4.57)$ and others which include Dressmaking, Crop Production, Automotive, etc. $(M=21.98, S D=3.99)$. This means that all students of all strands of the TVL track got scores ranging from 16-32 points out of the 80-item competency test given.

Finally, on the overall competency of the Senior High School students in General Mathematics, the students rate is fair $(M=24.88, S D=6.53)$. This indicates that the Senior High School students have fair competency in General Mathematics, which includes the learning competencies in Functions and their Graphs, Business Mathematics, and Logic Areas.

Table 2 presents the One-way Analysis of Variance (ANOVA) among the four strands of the Academic Track. The result shows that there was a significant difference on the competency of the students in General Mathematics among the four strands of the Academic Track $F(3,226)=$ 
48.467, $p=0.000$. Furthermore, post hoc result using the Scheffe-test revealed that STEM is significantly different to the other strands; ABM, GAS, and HUMMS at $(\mathrm{p}=0.000)$. Also, $A B M$ is significantly different from GA $(p=0.001)$ and HUMMS $(p=0.032)$. This implies that, among the strands of the academic track, STEM strand students got significantly higher scores on the 80-item competency test administered compared to the other three strands.

Table 3 presents the One-way Analysis of Variance (ANOVA) among the three strands of the Technical Vocational and Livelihood (TVL)Track. The result shows that there was a significant difference on the Competency in General Mathematics among the three strands of the Technical Vocational and Livelihood Tracks $F(2,192)=$ $18.901, p=0.000$. Furthermore, post hoc result using the Scheffe-test revealed that Computer Servicing System was significantly different from Home Economics $(p=0.000)$ and others $(\mathrm{p}=0.000)$. Moreover, no significant difference between the Home Economics and Others Strands $(p=0.588)$ was shown. This indicates that among the strands of the TVL track, CSS strand students got significantly higher scores on the 80-item competency test administered compared to the other strands.

Table 4 presents the t-test results for difference of the competency of senior high school students in General
Mathematics between Academic and Technical Vocational Livelihood (TVL) Track. The result indicate that there was a significant difference in the competency of the students in General Mathematics between the two tracks $(t(415.336)=5.52, p=0.000)$. This means that the academic track students got higher scores in the administered 80-item competency test compared to the TVL track students. The results further show that the Academic Track $(M=26.40)$ had a significantly higher mean score than the TVL track $(M=23.09)$.

Table 5 shows the 15 least learned competencies of the Senior High School Students in General Mathematics based on the administered 80-item Competency test. The table also reflects learning competencies' corresponding frequency or number of students who correctly answered each corresponding question. The least learned was determining the validity of categorical syllogism with only 52 students out of 425 who got the correct answer. This is followed by finding the domain and range of inverse function ( $\mathrm{f}=53$ ), then calculating the present value and period of deferral of a deferred annuity $(\mathrm{f}=63)$. Tied on the 14.5th spot are the learning competencies of representing a logarithmic function through its: (a) table of values, (b) graph, and (c) equation and finding the domain and range of an exponential function with 93 out of 425 students who correctly answered.

Table 1. Competency of Senior High School Students in the Academic and TVL tracks in General Mathematics

\begin{tabular}{lllll}
\hline Senior High School Track & $n$ & $S D$ & $M$ & Description \\
\hline Academic Track & & & & \\
ABM & 50 & 6.51 & 26.70 & Fair \\
HUMSS & 50 & 4.52 & 23.36 & Fair \\
GA & 70 & 4.50 & 22.37 & Fair \\
STEM & 60 & 6.62 & 33.40 & Satisfactory \\
TOTAL & 230 & 7.12 & 26.40 & Fair \\
TVL Track & & & Fair \\
CSS & 70 & 5.64 & 25.89 & Fair \\
HE & 65 & 4.57 & 21.09 & Fair \\
Others & 60 & 3.99 & 21.98 & Fair \\
TOTAL & 195 & 5.25 & 23.09 & Fair \\
Over-all & 425 & 6.53 & 24.88 & \\
\hline
\end{tabular}

Note: $64.01-80.00=$ Excellent $; 48.01-64.00=$ Very Satisfactory; 32.01-48.00 = Satisfactory; $16.01-32.00=$ Fair, 0-16.01 = Poor

Table 2. One-way Analysis of Variance (ANOVA) of the Competency in General Mathematics Among the 4 Strands of the Academic Track

\begin{tabular}{cccccc}
\hline Source of Variation & SS & Df & MS & $F$ & Sig \\
\hline Between Groups & 4542.633 & 3 & 1514.211 & $48.467^{*}$ & 0.000 \\
Within Groups & 7060.763 & 226 & 31.242 & & \\
Total & 11603.396 & 229 & & & \\
\hline
\end{tabular}

Note: $* p<0.001$ 
Table 3. One-way Analysis of Variance (ANOVA) of the Competency in General Mathematics Among the 3 Strands of the Technical Vocational and Livelihood (TVL) Track

\begin{tabular}{cccccc}
\hline Source of Variation & $S S$ & $D f$ & $M S$ & $F$ & $p$-value \\
Between Groups & 880.003 & 2 & 440.001 & $18.901^{*}$ & 0.000 \\
Within Groups & 4469.515 & 192 & 23.279 & & \\
Total & 5349.518 & 194 & & & \\
\hline
\end{tabular}

Note: $* p<0.001$

Table 4. The t-test Results for Difference of the Competency of Senior High School Students in General Mathematics between Academic and Technical Vocational Livelihood (TVL) Track

\begin{tabular}{|ccccccccc|}
\hline Group & $n$ & $M$ & $d f$ & $t$ & Sig & Mean & \multicolumn{9}{c|}{ \% confidence interval } \\
\hline Academic & 230 & 26.40 & & & & Difference & Lower & Upper \\
\hline & & & 415.336 & $5.52^{*}$ & 0.000 & 3.32 & 2.13 & 4.50 \\
\hline TVL & 195 & 23.09 & & & & & & \\
\hline
\end{tabular}

Note: ${ }^{*} p<0.001$

Table 5. Ranking Result of the Least Learned Learning Competencies of the SHS Students in General Mathematics $(n=425)$

\begin{tabular}{|c|c|c|c|}
\hline Learning Competencies & $F$ & $\%$ & Rank \\
\hline Determines the validity of categorical syllogisms. & 52 & 12.23 & 1 \\
\hline Finds the domain and range of an inverse function. & 53 & 12.47 & 2 \\
\hline Calculates the present value and period of deferral of a deferred annuity. & 63 & 14.82 & 3 \\
\hline Justifies mathematical and real-life statements using the different methods of proof and disproof. & 76 & 17.88 & 4 \\
\hline Illustrates the different methods of proof (direct and indirect) and disproof (indirect and by counterexample). & 77 & 18.12 & 5 \\
\hline Solves problems involving inverse functions. & 79 & 18.59 & 6 \\
\hline Finds the future value and present value of both simple annuities and general annuities. & 82 & 19.29 & 7 \\
\hline Illustrates the different methods of proof (direct and indirect) and disproof (indirect and by counterexample). & 83 & 19.53 & 8 \\
\hline Solves problems involving logarithmic functions, equations, and inequalities. & 84 & 19.76 & 9 \\
\hline Finds the future value and present value of both simple annuities and general annuities. & 85 & 20.00 & 10 \\
\hline Represents an inverse function through its: (a) table of values, and (b) graph. & 87 & 20.47 & 11 \\
\hline Determines the truth values of propositions. & 89 & 20.94 & 12 \\
\hline Solves problems involving exponential functions, equations, and inequalities. & 91 & 21.41 & 13 \\
\hline Represents a logarithmic function through its: (a) table of values, (b) graph, and (c) equation. & 93 & 21.88 & 14.5 \\
\hline Finds the domain and range of an exponential function. & 93 & 21.88 & 14.5 \\
\hline
\end{tabular}

\section{Discussion and Conclusion}

This study was conducted in one division of the Department of Education Region 8, Philippines, with 425 senior high school students from the seven public senior high schools. In this study, the researcher examined students' competency of senior high school students by strands and tracks.

The results of this study showed that senior high school students' competency in General Mathematics is "fair". Only the STEM strand of the academic track is "satisfactory" in competency. When the related literature is reviewed, this is parallel to the study of Herrera and Dio [11] about the prerequisite knowledge needed in General Mathematics for senior high school. It was revealed that Grade 10 students are moderately ready on $68 \%$ of the prerequisite competencies. This indicates that the students acquired the minimum knowledge and skills on the prerequisite competencies of General Mathematics. This may be the reason why the high school seniors got a fair competency for they only acquired the minimum prerequisite knowledge and skills in the subject matter. They further concluded that the over-all MPS of $40 \%$ denotes that the respondents are moderately ready for General Mathematics of Senior High School. Moreover, they discovered that $32 \%$ of the prerequisite competencies for senior high school as identified by the grade 10 Math teachers fall under the not ready category. This informs that the students did not acquire mastery of the prerequisite competencies. Hence, it was stressed out that students are not ready on the General Mathematics' topics.

Furthermore, there are still teachers who are not ready for senior high school. To note, $18.6 \%$ indicated that they 
are not ready, $2.8 \%$ expressed that they are uncertain and partially ready, and $4.3 \%$ did not give any comment on the survey given [12]. Also, Chua [13] highlighted that teachers were not ready during the implementation of the senior high school. He further noted that there was a huge gap among students' mathematical abilities, hence, having very heterogeneous classes, finding one approach that would suit all learners' styles and pace was very difficult. This may be one of the possible reasons why high school seniors got difficulty in General Mathematics, that is to say, in the first place, teachers themselves are still adjusting to the new curriculum.

Results further indicated that the STEM strand is significantly different in competency compared to the other strands in the academic track. This may be supported by the concepts presented on the study of Sison et al [14] who highlighted the focus of each strand of the academic track. It was pointed out that the Science, Technology, Engineering and Math (STEM) strand equips students with the knowledge and skills to solve tough problems, evaluate evidence, and make sense of the available information in creating solutions through invention and discovery to improve the way of life. The Humanities and Social Sciences (HUMSS) strand focuses on building a solid liberal arts foundation, exploration of the theoretical aspects of their chosen field and hands-on professional experience. The Accountancy, Business, and Management (ABM) strand includes Social/Applied learners who learn best by interacting with peers and even their teachers. The General Academic (GA) strand includes students who are undecided on which field they want to pursue in college. Also, those students with mathematics anxiety chose HUMSS as their career track because of the minimal math subjects being offered in their curriculum compared to ABM and STEM that offer additional Math subjects [15]. Aunzo and Lanticse [16] discovered that students who preferred STEM have higher Mathematics grade than those who prefer Arts and Design, General Academic (GA), and Humanities and Social Sciences (HUMSS).

On the TVL track, CSS is significantly different in competency compared to the other strands. The findings may support the idea presented by Magno and Piosang [7] about the inclinations of the strands of the TVL track. The Information and Communication Technology (ICT) strand like Computer Servicing System (CSS) that has inclinations on Mathematics, creative arts, information technology, and office work. The other strands like Home Economics (HE), Agri-fishery, and Industrial Arts are mostly inclined to manual labor, outdoor agriculture, physical/risk taking, protective and skilled trades.

Moreover, data revealed that the academic track students have significantly different competency compared to that of the TVL track. Findings of Guill et al [17] may support this claim. In their study for four years about ability grouping or tracking, they revealed that academic track students' intelligence score was significantly higher than the mean intelligence score of the matched group of non-academic track students. A parallel result was found out on students' effort by track. It was discovered out that Academic track is significantly different in their effort towards Math compared to the Vocational track [18]

On having those 15 least learned competencies, similar findings indicated that the least learned topics for functions are on verifying if a given relation is a function, and on graphing linear functions, quadratic functions and polynomial functions (24\%). In basic business mathematics, the least mastered prerequisite competency mathematics is solving word problems involving simple interest. For logic, writing proof turned out as the least mastered [11].

The fair competency of senior high school students in General Mathematics may indicate that senior high school learners have not yet mastered the necessary competencies in the subject matter as stipulated by the Department of Education. It may also show that their learning in the core subject-General Mathematics is not yet enough to get a satisfactory competency.

The STEM students appeared to be more knowledgeable in the area of Mathematics compared to the other strands in the academic track including ABM, GA, and HUMSS. It is possibly because STEM students show better ability in number and letter series, visual discrimination and Mathematics in general compared to the other strands, which have different abilities. Computer Servicing System (CSS) is shown to be more knowledgeable compared to Home Economics and other strands in the TVL track because their inclinations are also to mathematics, creative arts, information technology, and office work. Moreover, the academic track is significantly different from the TVL track because the former's inclination is into academe while the latter are more into skills development for vocational jobs.

The least learned competencies were found to be the last and highly analytical topics of the three main divisions of General Mathematics. The possible reasons why students had a hard time on these competencies were because of the difficulty of the topics, or those were not discussed.

The results of the assessment of the competency of the students in General Mathematics are alarming. Teachers may find ways to deal with the students in a more engaging manner. They may be able to consider using other teaching strategies and/or revisit the curriculum plan stipulated for better instructional purposes.

Learners may try to strive harder in learning the math concepts. They are encouraged to be well informed on how their performance in the classroom and/or national assessment examinations affects themselves and the school. They may be reminded of their responsibility that taking exams in any form is not just a measure of their 
competence but also that of the teachers' and the school system as well.

Curriculum planners including, head teachers, department heads, principals, and policy makers including the Department of Education officials may consider few revisions on the stipulated curriculum guides especially that the results revealed that senior high school students only have "fair" competency in General Mathematics. They may consider restructuring the math topics per subject area and plan a better way to have a more effective and efficient teaching-learning process.

It is further recommended for a more detailed assessment review, which includes qualitative means in soliciting data for deeper understanding to support the quantitative data provided.

\section{Acknowledgements}

The corresponding author is very grateful to the Department of Science and Technology - Science Education Institute Capacity Building Program for Science and Mathematics Educators (DOST-SEI CBPSME) for the Scholarship and dissertation grant and to Visayas State University (VSU) for the financial assistance.

\section{REFERENCES}

[1] Wiliam, D. What is assessment for learning?. Studies in Educational Evaluation, 37(1), 3-14, 2011. doi: https://doi.org/10.1016/j.stueduc.2011.03.001

[2] DepEd Order no. 8, s. 2015. Policy guidelines on classroom assessment for the $\mathrm{K}$ to 12 basic education program.

[3] Hartel, R.W., \& Foegeding, E.A. Learning: Objectives, Competencies, or Outcomes?. Journal of Food Science Education, 3, 69-70, 2004. doi: 10.1111/j.1541-4329.2004.tb00047.x

[4] Laine, R., Cohen, M., Nielson, K., \& Palmer, I. (2015). Expanding student success: A primer on competency-Based education from Kindergarten through higher education. Available online from http://www.nga.org/cms/home/nga-center-for-best-practice $\mathrm{s} /$ center-divisions/page-edu-division/col2-content/list---edu -left/list-edu-highlight/content-reference-2@/expanding-st udent-success-a-prim.html

[5] Horn, M. B., \& Staker, H. (2015). Blended: Using disruptive innovation to improve schools. San Francisco, CA, Jossey-Bass.

[6] Sturgis, C. \& Casey, K. (2018). Quality principles for competency-based education. Available online from: https://www.competencyworks.org/wp-content/uploads/20 18/10/Quality-Principles-Book.pdf Quality

[7] Magno, C. \& Piosang, T. (2016). Assessment schemes in the senior high school in the Philippine basic education. Educational Measurement and Evaluation Review, 7(1), 66-87, 2016.

[8] Department of Education. (2013). An introductory guide to senior high school. Available online from http://www.deped.gov.ph/sites/default/files/SHS\%20Stude nt\%20Primer_Colored $\% 20$ HiRes.pdf

[9] CHED. (2016). K to 12 transition program. Available online from: https://ched.gov.ph/k-12-project-management-unit/

[10] Stangor, C. (2011). Research methods for the behavioural sciences (4th ed.). Mountain View, CA: Cengage.

[11] Herrera, C., \& Dio, R. (2016). Extent of readiness of grade 10 students for general Mathematics of senior high school in Sorsogon City, Philippines. Asia Pacific Journal of Education, Arts and Sciences, 3(4), 1-8, 2016. Retrieved from: www.apjeas.apjmr.com

[12] Acosta, I., \& Acosta, A. (2016). Teachers' perceptions on senior high school readiness of higher education institutions in the Philippines. Universal Journal of Educational Research, 10 (4), 2447-2462. doi: 10.13189/ujer.2016.041024

[13] Chua, V.C. (2015). Assessment of the Mathematics curriculum in the SHS modelling program. doi: 10.13140/RG.2.1.2340.7849

[14] Sison, M., Galvez, R., \& Coronel J.M. (2017). Assessing the learning styles of senior high school students of $\mathrm{La}$ Consolacion University Philippines: Implications in the teaching-learning process. International Journal of Education and Research, 5(12), 45-52, 2017. Retrieved from: www.ijern.com

[15] Espino, M., Pereda, J., Recon, J., Perculeza, E., \& Umali, C. Mathematics anxiety and its impact on the course and career choice of grade 11 students. International Journal of Education, Psychology and Counselling, 2(5), 99-119, 2017. Retrieved from: www.ijepc.com

[16] Aunzo, R., \& Lanticse, C. (2015). Learning Mathematics and Mathematics performance: Analysis with their preferred track in the senior high during the grade 11 in the K-12 implementation. World Journal of Educational Research, 2(4), 1- 10, 2015. Retrieved from: http://www.wjer.org/

[17] Guill, K., Lüdtkeb, O., \& Koller O. (2017). Academic tracking is related to gains in students' intelligence over four years: Evidence from a propensity score matching study. Learning and Instruction, 47, 43-52, 2017. Retrieved from: https://doi.org/10.1016/j.learninstruc.2016.10.001

[18] Carbonaro, W. (2015). Tracking, students' effort, and academic achievement. Sociology of Education, 78(1), 27-49. Retrieved from: https://doi.org/10.1177/003804070507800102 